\title{
Crescimento, desenvolvimento e retardamento da senescência foliar em girassol de vaso (Helianthus annuus L.): fontes e doses de nitrogênio
}

\author{
Growth, development and delay of leaf senescence in pot-grown sunflower (Helianthus annuus L.): sources \\ and rates of nitrogen
}

\author{
Joelma Dutra Fagundes ${ }^{I}$ Gisele Santiago' ${ }^{I}$ Anderson Machado de Mello ${ }^{I}$ Rogério Antônio Bellé ${ }^{I I}$ \\ Nereu Augusto Streck ${ }^{\text {II }}$
}

RESUMO

O girassol é a quarta oleaginosa em produção de grãos no mundo e alguns genótipos são usados com finalidade ornamental para flor de corte e de vaso (girassol de vaso). O objetivo do trabalho foi avaliar o efeito de diferentes fontes $e$ doses de nitrogênio sobre alguns parâmetros de crescimento, desenvolvimento e no retardamento da senescência das folhas basais em girassol de vaso. Um experimento foi conduzido em casa de vegetação, em Santa Maria, RS. Os tratamentos foram: uréia, nitrato de amônio e nitrato de cálcio nas doses de 0, 50, 100 e $150 \mathrm{mg} \mathrm{L}^{-1}$ de $\mathrm{N}$ na solução de fertirrigação, com duas aplicações semanais. $O$ experimento foi um bi-fatorial (fontes $e$ doses de $N$ ) no delineamento inteiramente casualizado, com seis repetições. Cada repetição foi um vaso $n^{0} 15(1,3 \mathrm{~L}, 15 \mathrm{~cm}$ de altura) com uma planta por vaso. As variáveis analisadas foram: número final de folhas, altura final de plantas, porcentagem de folhas senescentes no ponto de venda, porcentagem de folhas senescentes no final de vida de vaso, área foliar total da planta, filocrono e a soma térmica acumulada da emergência ao botão visível e da emergência ao ponto de venda. A fonte de $N$ tem influência sobre a área foliar do girassol de vaso, sendo a uréia recomendável para o maior crescimento das folhas. A dose de $N$ em torno de $100 \mathrm{mg} \mathrm{L}^{-1}$ aplicada duas vezes por semana via fertirrigação favorece características desejáveis para a comercialização, como precocidade e retardamento da senescência das folhas.

Palavras-chave: girassol, nitrogênio, fenologia, emissão de folhas.

\section{ABSTRACT}

Sunflower is the fourth oil grain crop grown worldwide and some genotypes are used with ornamental purpose as cut and pot-grown flower. The objective of this study was to evaluate the effect of different sources and rates of

\begin{abstract}
nitrogen on some growth and developmental parameters, and on the delay of leaf senescence in pot-grown sunflower. An experiment was carried out inside a greenhouse in Santa Maria, RS, Brazil. Treatments were: urea, ammonium nitrate and calcium nitrate at rates of $0,50,100$ and $150 \mathrm{mg} \mathrm{L}^{-1}$ of $N$ in the fertigation solution, with two weekly applications. The experiment was a two-factorial (sources and rates of $N$ ) in a completely randomized design with six replications. Each replication was a number 15 pot $(1.5 \mathrm{~L}, 15 \mathrm{~cm}$ height) with one plant/pot. The variables analyzed were: final leaf number, final plant height, percentage of senescent leaves at selling stage and at the end of vase life, total leaf area per plant, phyllochron, and the thermal time from emergency to visible bud and from emergency to selling stage. The $N$ source influences leaf area of pot-grown sunflower, with urea being recommend for higher leaf growth. The rate of around $100 \mathrm{mg} L^{-1}$ of $N$ applied twice a week through fertigation promoted desirable characteristics for commercialization such as earliness and delay of leaf senescence.
\end{abstract}

Key words: sunflower, nitrogen, phenology, leaf appearance.

\section{INTRODUÇÃO}

O girassol (Helianthus annus L.), família Asteraceae, tem origem na América do Norte e atualmente é cultivado em todos os continentes, em uma área que atinge aproximadamente 18 milhões de hectares (EMBRAPA, 2002). A cultura do girassol destaca-se como a quarta oleaginosa na produção de grãos e a quinta em área cultivada no mundo (CASTRO et al., 1997). Além da produção de grãos, o girassol está sendo também amplamente cultivado para a

\footnotetext{
IPrograma de Pós-graduação em Agronomia, Universidade Federal de Santa Maria (UFSM), Santa Maria, RS, Brasil.

IIDepartamento de Fitotecnia, Centro de Ciências Rurais (CCR), UFSM, 97105-900, Santa Maria, RS, Brasil. E-mail: nstreck1@smail.ufsm.br. Autor para correspondência.
} 
produção de flores de corte e de vaso (SCHOELLHORN et al., 2003).

Crescimento e desenvolvimento vegetal são processos independentes que podem ocorrer simultaneamente ou não (WILHELM \& McMASTER, 1995; STRECK et al., 2003). Enquanto crescimento vegetal se refere a mudanças irreversíveis de dimensões físicas de órgãos da planta como massa, volume, comprimento e área, desenvolvimento vegetal envolve a diferenciação celular, a morfogênese, o aparecimento e a senescência de órgãos (HODGES, 1991; WILHELM \& McMASTER, 1995). Assim, uma planta crescendo não necessariamente está se desenvolvendo e viceversa. O crescimento e o desenvolvimento das culturas são o resultado de fatores genéticos e ambientais, a quantificação dos fatores ambientais que afetam estes dois processos oportuniza a possibilidade de melhoria das técnicas aplicadas à produção. A nutrição mineral é um importante fator ambiental, sendo o nitrogênio o macronutriente exigido em maior quantidade pelas culturas agrícolas, pois o crescimento e desenvolvimento das plantas são altamente dependentes da disponibilidade deste nutriente. Esta alta dependência ocorre devido às funções do $\mathrm{N}$ no metabolismo das plantas, participando como constituinte da molécula de clorofila, ácidos nucléicos, aminoácidos e proteínas (TAIZ \& ZEIGER, 2004).

Existem diferentes fontes de $\mathrm{N}$ que podem ser usadas na adubação nitrogenada das culturas, tanto a campo como em vaso (JENDIROBA \& CÂMARA, 1994; SOARES et al., 1999, ANDREOTTI et al., 2005). Na sua escolha, deve-se levar em consideração a quantidade e a forma de $\mathrm{N}$ e o custo do adubo. $\mathrm{Na}$ floricultura, como em muitas outras culturas agrícolas, a relação custo/benefício da fonte e da dose de N são importantes na viabilização do empreendimento. $\mathrm{Na}$ floricultura, importa ainda a qualidade do adubo, sua solubilidade e reação na solução.

A remobilização do $\mathrm{N}$ na planta inicia com o processo de formação de flores e leva inicialmente à senescência das folhas basais, caracterizada visualmente pelo amarelecimento dessas, seguida de morte (GUITMAN et al., 1991; SMART, 1994; CRAFTSBRANDER et al., 1998). Na comercialização de girassol em vaso, é comum observar-se folhas basais amarelas, cuja presença afeta o visual e diminui a qualidade do produto, sendo que a diminuição da qualidade é proporcional ao número de folhas senescentes na planta (REID, 2004). Assim, é possível que o tipo de fonte e a dose de $\mathrm{N}$ possam interferir na velocidade do processo de senescência, o que abre perspectivas de melhoria da qualidade das plantas na comercialização.
Na bibliografia consultada, não foram encontradas informações a respeito do efeito do $\mathrm{N}$ sobre parâmetros de crescimento, desenvolvimento e senescência foliar do girassol de vaso, o que constituiu o incentivo para este esforço científico. O objetivo do trabalho foi avaliar o efeito de diferentes fontes e doses de nitrogênio sobre alguns parâmetros de crescimento, desenvolvimento e no retardamento da senescência foliar em girassol de vaso.

\section{MATERIAL E MÉTODOS}

Um experimento foi conduzido em uma casa de vegetação instalada no Departamento de Fitotecnia da Universidade Federal de Santa Maria - UFSM, Santa Maria, RS (latitude 29 43'S, longitude 53 $43^{\prime} \mathrm{W}$ e altitude $95 \mathrm{~m}$ ). Foram utilizadas sementes de girassol dobrado amarelo anão cultivar "Double Sungold" adquiridas da empresa ISLA. A semeadura foi em 02/ 10/2005, em vaso número ํㅜㄴ 15 (1,3 L, 15cm de altura), colocando-se cinco sementes por vaso. A mistura usada como substrato constitui-se de $60 \%$ de substrato comercial Plantmax HT e $40 \%$ de casca de arroz carbonizada. A análise química da mistura (análise básica + micronutrientes) realizada no laboratório de análises de solos da UFSM apresentou os seguintes resultados: $\mathrm{pH}$ (água) 5,8, 16,1 $\mathrm{cmol}_{\mathrm{c}} \mathrm{dm}^{-3}$ de $\mathrm{Ca}$, 5,8 $\mathrm{cmol}_{\mathrm{c}} \mathrm{dm}^{-3}$ de $\mathrm{Mg}, 23,9 \mathrm{cmol}_{\mathrm{c}} \mathrm{dm}^{-3}$ de $\mathrm{CTC}_{\text {efetiva, }}$, índice SMP 6,1, 14,1\% (m/v) de matéria orgânica, 76mg $\mathrm{dm}^{-3}$ de P-Mehlich, 27,6 $\mathrm{cmol}_{\mathrm{c}} \mathrm{dm}^{-3} \mathrm{de} \mathrm{CTC}_{\mathrm{pH}} 704 \mathrm{mg}$ $\mathrm{dm}^{-3}$ de K, $142,3 \mathrm{mg} \mathrm{dm}^{-3}$ de S, $1 \mathrm{mg} \mathrm{dm}^{-3}$ de Cu', 8,7mg $\mathrm{dm}^{-3}$ de Zn e 3,9mg dm${ }^{-3}$ de B. A análise de densidade apresentou o seguinte resultado: $294,0 \mathrm{~kg} \mathrm{~m}^{-3}$. Os vasos permaneceram sobre três bancadas a $70 \mathrm{~cm}$ de altura. Foi considerado como o dia da emergência quando 50\% das plântulas tinham seus cotilédones acima da superfície do substrato. Sete dias após a emergência (EM), foi realizado um raleio, deixando-se uma planta por vaso.

Durante o período experimental, foram medidas diariamente a temperatura mínima e máxima do ar com termômetro de mínima de álcool e termômetro de máxima de mercúrio, respectivamente, instalados no interior de um miniabrigo meteorológico na altura das bancadas. As irrigações dos vasos foram diárias e foram realizadas duas pulverizações usando-se o acaricida Vertimec (Abamectina) na dose de $1 \mathrm{ml} \mathrm{L}^{-1}$. As brotações laterais foram eliminadas quando as plantas estavam no estágio R5 (começo da floração) da escala de SCHNEITER \& MILLER (1981).

Os tratamentos utilizados constaram de três fontes de nitrogênio na solução usada para fertirrigação dos vasos (uréia, nitrato de amônio e nitrato de cálcio) 
nas doses de $0,50,100,150 \mathrm{mg} \mathrm{L}^{-1}$ de $\mathrm{N}$, não havendo adubação complementar. As relações dos valores $\mathrm{N}: \mathrm{K}$ em cada tratamento foram as seguintes: 1:14, 1:7 e 1:4,7. $\mathrm{O}$ experimento foi um bifatorial (fontes e doses de $\mathrm{N}$ ) no delineamento inteiramente casualizado, com seis repetições. Cada repetição era um vaso com uma planta. Um volume de $200 \mathrm{ml}$ de solução (água + adubo nitrogenado) por vaso foi aplicado duas vezes por semana (segunda-feira e sexta-feira), a partir da segunda semana após a emergência até o estágio R4 (antese) da escala de desenvolvimento de SCHNEITER \& MILLER (1981).

Como parâmetros de crescimento, foram medidas em todas as plantas a altura final da planta (distância da superfície do substrato até a inserção do capítulo) e o comprimento e largura das folhas individuais após sua completa expansão. Com as medidas de comprimento (C) e largura (L) das folhas completamente expandidas, foi determinada a área de cada folha pela relação AF $=\mathrm{C}$ x L x K, em que K é o fator de forma ou fator de correção. $\mathrm{O}$ valor de $\mathrm{K}$ foi estimado usando-se 86 folhas de cinco plantas cultivadas concomitantemente ao experimento, as quais foram submetidas aos mesmos tratos culturais das demais plantas, sendo obtido um valor de $K=0,70$. A área foliar total da planta foi calculada pelo somatório das áreas das folhas individuais.

Foi contado três vezes por semana o número de folhas visíveis acumuladas na haste principal (NF) e o número final de folhas em cada planta. Foi considerada como folha visível aquela com comprimento igual ou maior do que $1 \mathrm{~cm}$. As datas dos seguintes estádios de desenvolvimento foram determinadas em cada planta: botão visível (BV, considerado quando o botão tinha $1 \mathrm{~cm}$ de diâmetro), ponto de venda (PV, considerado quando o capítulo tinha $50 \%$ das flores abertas, correspondendo ao estágio R5.5 da escala de SCHNEITER \& MILLER, 1981), capítulo senescente (CS, considerado quando as flores do raio estavam murchas, correspondendo ao estágio R6 da escala SCHNEITER \& MILLER, 1981). O período de vida de vaso foi considerado de PV a CS. Foi também contado o número de folhas senescentes (amarelas) no PV e CS.

A soma térmica diária (STd, ${ }^{\circ} \mathrm{C}$ dia) foi calculada por (GILMORE \& ROGERS, 1958; ARNOLD, 1960; STRECK et al., 2005a):

$\mathrm{STd}=\left(\mathrm{T}_{\text {med }}-\mathrm{T}_{\mathrm{b}}\right) \cdot 1$ dia, quando $\mathrm{T}_{\mathrm{b}}<\mathrm{T}_{\text {med }} \leq \mathrm{Tot}$

$\mathrm{STd}=\left[(\right.$ Tot $-\mathrm{Tb}) .($ Tmed $-\mathrm{Tmax}) /\left(\right.$ Tot $\left.\left.-\mathrm{T}_{\max }\right)\right] .1 \mathrm{dia}$, quando Tot $\leq$ Tmed $\leq$ Tmax

em que Tb é a temperatura base, Tot é a temperatura ótima e $\mathrm{T}_{\max }$ é a temperatura máxima para o desenvolvimento do girassol e $\mathrm{T}_{\text {med }}$ é a temperatura média do ar calculada pela média aritmética entre a temperatura mínima e a temperatura máxima diária do ar. Utilizou-se $\mathrm{T}_{\mathrm{b}}=7,2^{\circ} \mathrm{C}$ (SANGOI \& SILVA, 1986), $\mathrm{T}_{\mathrm{ot}}=$ $27^{\circ} \mathrm{C}$ e $\mathrm{T}_{\max }=34^{\circ} \mathrm{C}$ (EMBRAPA, 2002). Estas temperaturas cardinais são do girassol cultivado a campo para grãos e foram adotadas neste estudo, pois o girassol cultivado é da mesma espécie do girassol de vaso e por não ter sido encontrada referência na literatura consultada sobre as temperaturas cardinais do girassol de vaso. Optou-se pelo decréscimo de STd quando $\mathrm{T}_{\text {med }}$ era superior a $\mathrm{T}_{\mathrm{ot}}=27^{\circ} \mathrm{C}$ (eq. 2), como em STRECK et al. (2005a), pois freqüentemente a temperatura do ar no interior da casa de vegetação durante o período diurno ultrapassou o valor de $\mathrm{T}_{\mathrm{ot}}$.

A soma térmica acumulada (STa, ${ }^{\circ} \mathrm{C}$ dia) a partir da emergência foi calculada por:

$\mathrm{STa}=\sum \mathrm{STd}$

Com estes dados, calculou-se a STa das fases EM-BV e EM-PV e do filocrono, definido como o intervalo de tempo entre o aparecimento de folhas sucessivas em uma haste (KLEPPER et al., 1982; RICKMAN \& KLEPPER, 1995; WILHELM \& McMASTER, 1995). O filocrono foi estimado como sendo o inverso do coeficiente angular da regressão linear entre NF e STa (KLEPPER et al., 1982; BAKER \& REDDY, 2001; STRECK et al., 2005a,b). A soma térmica, em vez de dias do calendário civil, foi usada, pois é uma medida mais realística de tempo biológico em plantas (STRECK et al., 2005a,b).

Foi avaliada também a proporcionalidade entre a planta e o vaso (padrão de qualidade) usandose os critérios utilizados para crisântemo (MOTOS \& OLIVEIRA, 1990), pois, na literatura consultada, inexiste esse tipo de informação para girassol de vaso.

Os dados foram submetidos à análise de variância e de regressão com o auxílio do Software científico NTIA (EMBRAPA, 1997). Quando houve ajuste ao modelo quadrático $\left(y=b_{0}+b_{1} X+b_{2} X^{2}\right)$, foi calculado o ponto de máxima eficiência técnica - MET $\left(\mathrm{X}=\mathrm{b}_{1} / 2 \mathrm{~b}_{2}\right)$

\section{RESULTADOS E DISCUSSÃO}

Houve efeito significativo $(\mathrm{P}=5 \%)$ das doses de $\mathrm{N}$ para todas as variáveis medidas, exceto para soma térmica da fase EM-BV. Com relação às fontes de N, houve efeito significativo para área foliar e soma térmica da fase EM-PV. Não houve interação significativa a 5\% de probabilidade de erro entre doses e fontes de nitrogênio para todas as variáveis, exceto para área foliar total da planta. Baseada nos resultados das análises de variância e de regressão, a interpretação dos resultados foi realizada conforme os dados apresentados na figura 1 . 

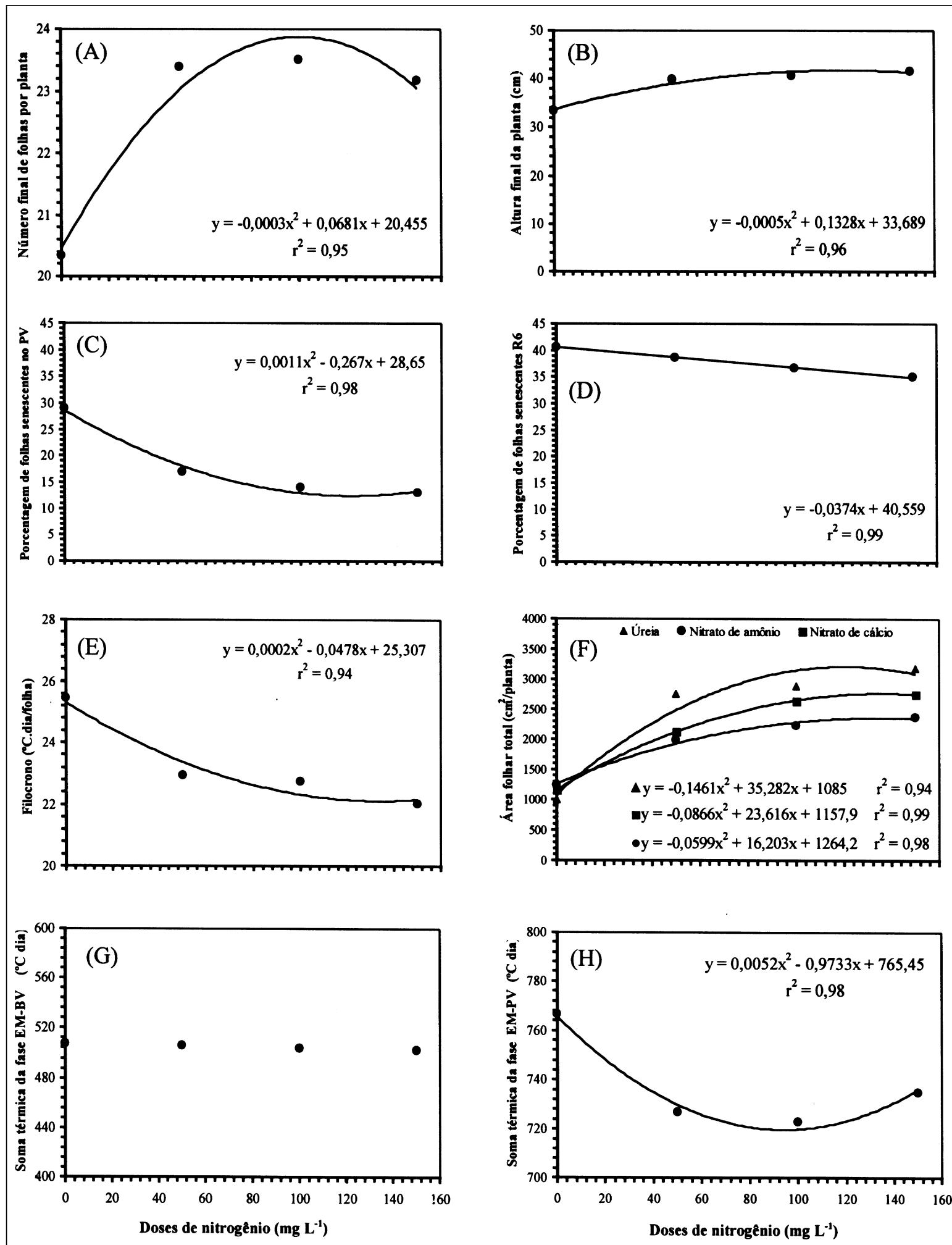

Figura 1 -Relação entre doses de nitrogênio e número final de folhas por haste (A), altura final da planta (B), porcentagem de folhas senescentes no PV (C), porcentagem de folhas senescentes no R6 (D), filocrono (E), área folhar total (F), soma térmica da fase EM-BV (G) e soma térmica da fase EM-PV $(\mathrm{H})$. EM= emergência, $\mathrm{PV}=$ ponto de venda, R6= capítulo senescente. Cada ponto é a média de seis valores $(\mathrm{n}=6)$. Santa Maria, RS, 2005. 
A análise de regressão para a variável número final de folhas/planta em relação às doses de $\mathrm{N}$ mostrou que o melhor ajuste foi representado por uma curva quadrática negativa (Figura 1A). Observou-se que o aumento da dose resultou num aumento no número final de folhas, onde o incremento máximo (24 folhas) foi estimado na dose de $113,5 \mathrm{mg} \mathrm{L}^{-1}$ de N. A partir do ponto de máxima existe uma tendência à redução no número final de folhas.

A altura final de plantas também foi influenciada pelas doses de $\mathrm{N}$, sendo a relação mais bem ajustada pelo modelo quadrático negativo (Figura 1B). As plantas testemunhas tiveram alturas em torno de 33,4cm e as que receberam a dose máxima (150 $\left.\mathrm{mg} \mathrm{L}^{-1}\right)$ atingiram os $41,5 \mathrm{~cm}$, um incremento de $8 \mathrm{~cm}$. Esse aumento de altura pode ser explicado pelo aumento do número de folhas (20,3 para 23,2 folhas) e de seus respectivos entrenós, que é pequeno, devido ao caráter anão da cultivar e à alta radiação solar durante o ciclo de crescimento, resultando em pouca competição entre vasos pela baixa densidade desses na bancada. No entanto, esse valor foi suficiente para afetar a qualidade de vaso pela alteração da proporcionalidade entre a altura da planta/altura do vaso. Segundo MOTOS \& OLIVEIRA (1990), as melhores alturas de plantas, para o vaso 15 , devem ficar compreendidas entre 23 e $35 \mathrm{~cm}$ e, neste estudo, somente as plantas testemunhas preencheram esse critério. Para os demais tratamentos, as plantas ficaram desproporcionais em relação à altura do vaso segundo este critério.

A relação da porcentagem de folhas senescentes no PV em função da dose de $\mathrm{N}$ foi mais bem ajustada por uma curva quadrática positiva (Figura $1 \mathrm{C})$, sendo que a porcentagem de folhas senescentes diminuiu à medida que a dose de $\mathrm{N}$ aumentou até o valor de 132,4mg $\mathrm{L}^{-1}$. Essa redução da senescência indica que o aumento no fornecimento de $\mathrm{N}$ foi suficiente para estimular o crescimento da planta (JOEL et al., 1997), aumentar a capacidade fotossintética das folhas através de um aumento na quantidade de estroma e proteínas tilacóides nas folhas e manter folhas verdes por mais tempo (EVANS \& TERASHIMA, 1988; FREDEEN et al. 1991; MAKINO et al., 1992). Já ao observar-se esse mesmo parâmetro para uma fase mais avançada, em R6, que corresponde ao final da vida de vaso ou capítulo senescente (Figura 1D), verifica-se que a diferença entre as doses caiu para pouco mais de $5 \%$. Esse processo de aceleração da senescência foliar com a maturação da planta é esperado e ocorre devido a altas quantidades de nitrogênio que são mobilizadas das folhas para outros tecidos que estão em crescimento como, por exemplo, as flores (GUITMAN et al., 1991; SMART, 1994; CRAFTS-BRANDER et al., 1998). A senescência das folhas é um fator negativo do ponto de vista da comercialização das plantas de girassol de vaso. No presente estudo, as plantas que não receberam nitrogênio suplementar apresentaram um grande número de folhas senescentes (30\%) por vaso no PV, o que indica a necessidade de suplementar este nutriente, e a suplementação de $\mathrm{N}$ retardou a senescência das folhas, aspecto positivo para qualidade da planta na comercialização.

A relação entre o número de folhas acumuladas na haste principal e a soma térmica acumulada a partir da emergência foi linear (dados não mostrados), com um $r^{2}$ variando de 0,95 a 0,99 para todos os tratamentos. Estes altos valores de $\mathrm{r}^{2}$ indicam que, em girassol de vaso, a emissão de folhas está fortemente relacionada com a temperatura do ar representada pelo acúmulo de graus-dia, como tem sido relatado para outras espécies como trigo, melão e cártamo (BAKER et al., 1986; BAKER \& REDDY, 2001; STRECK et al; 2005a,b). Portanto, a estimativa do filocrono pelo método da regressão linear é uma metodologia apropriada.

O filocrono é um importante parâmetro de desenvolvimento vegetal, pois refere-se à velocidade de emissão de folhas nas plantas, que são responsáveis pela interceptação e absorção da radiação solar. O filocrono estimado nas diferentes doses de $\mathrm{N}$ foi mais bem ajustado por uma curva quadrática positiva (Figura 1E). As plantas cultivadas sem $\mathrm{N}$ suplementar foram as que apresentaram o maior filocrono $\left(25,4^{\circ} \mathrm{C}\right.$ dia folha $\left.{ }^{-1}\right)$, ou seja, menor velocidade de emissão de folhas, enquanto que as plantas que receberam a maior dose foram as que emitiram folhas mais rapidamente $\left(22,0^{\circ} \mathrm{C}\right.$ dia folha-1 ${ }^{-1}$. Esses valores de filocrono são similares aos obtidos por VILLALOBOS et al. (1996) para genótipos de girassol cultivados para grãos cujos valores ficaram entre 20 e $25^{\circ} \mathrm{C}$ dia folha ${ }^{-1}$. Esse comportamento em que o fornecimento de $\mathrm{N}$ interfere no filocrono também foi observado em plantas de trigo (KIRBY, 1995).

A variável área foliar total da planta apresentou uma resposta quadrática negativa com a fonte de $\mathrm{N}$ (Figura 1F), mostrando que o aumento da dose aumentou a área foliar para todas as fontes. O tamanho de folha está relacionado ao suprimento de $\mathrm{N}$ para elongação e/ou divisão celular (SKINNER \& NELSON, 1995; GARCEZ NETO et al., 2002). O nitrogênio influencia não só a taxa de expansão, mas principalmente a divisão celular, determinando, desta forma, o tamanho final das folhas, fazendo com que o nitrogênio seja um dos fatores determinantes da taxa de acúmulo de biomassa (FERNÁNDEZ et al., 1994).

Entre as fontes de $\mathrm{N}$, o nitrato foi aquela que produziu a menor área foliar, enquanto que a fonte 
de uréia foi a que produziu as maiores folhas. Uma possível hipótese para explicar estes resultados pode estar no comportamento iônico das fontes envolvidas; o íon amônio, sendo um cátion, permanece junto ao substrato em forma trocável adsorvido pelas cargas negativas do mesmo. Já o nitrato, por ter carga negativa, é repelido pela superfície das partículas, permanecendo na solução, sendo assim muito móvel (RAIJ, 1991), e assim é 100 vezes mais passível de lixiviação que o amônio (MENGUEL \& KIRKBY, 1987). Como o ensaio ocorreu em período quente do ano, esse era irrigado com freqüência (duas vezes por dia), o que pode ter lixiviado mais o nitrato, tornando-o menos disponível à planta o que se repercutiu na redução da área foliar.

Pode-se supor que a menor resposta em área foliar na combinação do nitrato mais amônia pode ser devida à lixiviação e/ou ao comprometimento da absorção de nitrato por competitividade reduzida causada pelo amônio, mas o nitrato não interfere na absorção de amônio (MENGUEL \& KIRKBY, 1987). Já o tratamento com nitrato de cálcio pode ter causado uma elevação de $\mathrm{pH}$ pelo acúmulo de cálcio no substrato, com isso reduzindo a disponibilidade do íon nitrato à absorção. Pois para MENGUEL \& KIRKBY (1987), este é mais bem, absorvido em meio com pH baixo.

Tais resultados vêm ao encontro das recomendações de fertilização nitrogenada para o amor perfeito (Viola $X$ wittrokiana), no qual a fonte só nítrica produz plantas pequenas, enquanto que a aplicação de $\mathrm{N}$ ora amoniacal, ora nítrica favorece a expansão foliar e a elongação da haste de forma adequada (HEALY, 1998).

A soma térmica da fase EM-BV não foi afetada pela dose e fonte de N (Figura 1G). Já a soma térmica da fase EM-PV foi afetada pelas fontes de N. As plantas com uréia e nitrato de amônio tiveram significativamente maior duração da fase EM-PV ( $741,1^{\circ} \mathrm{C}$ dia e $742,9^{\circ} \mathrm{C}$ dia, respectivamente), do que as plantas com nitrato de cálcio $\left(719,4^{\circ} \mathrm{C}\right.$ dia). No entanto, esta diferença de duração desta fase em dias do calendário civil foi pequena, cerca de um dia, sendo, portanto, desprezível para fins de manejo da cultura, a não ser que o custo de produção de um dia a mais seja significativo economicamente.

$\mathrm{O}$ efeito da dose de $\mathrm{N}$ sobre a duração da fase EM-PV (Figura 1H) mostrou um comportamento quadrático positivo, no qual as plantas sem $\mathrm{N}$ suplementar foram as que necessitaram de maior soma térmica para venda $\left(768^{\circ} \mathrm{C}\right.$ dia). Em torno da dose de $100 \mathrm{mg} \mathrm{L}^{-1}$, observou-se que as plantas foram mais precoces em cerca de dois dias, e quando a dose de $\mathrm{N}$ aumentou para $150 \mathrm{mg} \mathrm{L}^{-1}$, também houve necessidade de maior acúmulo de temperatura para PV. Como não houve efeito das doses de $\mathrm{N}$ sobre a fase EM-BV (Figura 1G), o efeito sobre a fase EM-PV (Figura 1H) é explicado pelo efeito das doses de $\mathrm{N}$ sobre a fase BVPV. O baixo fornecimento de $\mathrm{N}$ no tratamento sem suplementação de $\mathrm{N}$ retardou a abertura das flores do capítulo, critério utilizado para definir o PV. Já o suplemento de $\mathrm{N}$ acelerou a abertura das flores do capítulo, resultando em ganho de precocidade para comercialização das plantas. Este ganho de precocidade foi em torno de $40^{\circ} \mathrm{C}$ dia, o que, em dias do calendário civil, pode representar dois a cinco dias, dependendo da temperatura.

\section{CONCLUSÃO}

A fonte de $\mathrm{N}$ tem influência sobre a área foliar do girassol de vaso, sendo a uréia recomendável para o maior crescimento das folhas. A dose de $\mathrm{N}$ em torno de $100 \mathrm{mg} \mathrm{L}^{-1}$ aplicada duas vezes por semana via fertirrigação favorece características desejáveis para a comercialização como precocidade e retardamento da senescência das folhas.

\section{AGRADECIMENTOS}

À Coordenação de Aperfeiçoamento de Pessoal de Ensino Superior (CAPES), pelas bolsas de estudo. Ao Conselho Nacional de Desenvolvimento Científico e Tecnológico (CNPq), pela bolsa de Produtividade em Pesquisa. Aos consultores Ad Hoc, pelas valiosas sugestões e comentários em versões anteriores do manuscrito.

\section{REFERÊNCIAS}

ANDREOTTI, M. et al. Fontes de nitrogênio e modos de adubação em cobertura sobre a produtividade de feijão (Phaseolus vulgaris L.) na "safra das águas". Acta Scientiarum, Maringá, v.27, n.4, p.595-602, 2005.

ARNOLD, C.Y. Maximum-miminum temperature as a basis for computing heat units. Proceedings of the American Society for Horticultural Science, Boston, v.76, n.1, p.682692, 1960 .

BAKER, J.T. et al. Effects of temperature on leaf appearance in spring and winter wheat cultivars. Agronomy Journal, Madison, v.78, p.605-613, 1986.

BAKER, J.T.; REDDY, V.R. Temperature effects on phenological development and yield of muskmelon. Annals of Botany, Oxford, v.87, p.605-613, 2001.

CASTRO, C. et al. A cultura do girassol. Londrina: EMBRAPA/ CNPS, 1997. 36p. (Circular Técnica, 13).

CRAFTS-BRANDER, S.J. et al. Influence of nitrogen deficiency on senescence and the amounts of RNA and proteins in wheat leaves. Physiologia Plantarum, Oxford, v.102, p.192-200, 1998.

EMBRAPA. Ambiente de software NTIA, versão 4.2.2: manual do usuário. Campinas: Centro Nacional de Pesquisa Tecnológica em Informática para a Agricultura, 1997. 258p.

Ciência Rural, v.37, n.4, jul-ago, 2007. 
EMBRAPA - Empresa Brasileira de Pesquisa Agropecuária. Resultado de pesquisa da EMBRAPA Soja - 2001: girassol e trigo. Londrina: EMBRAPA Soja, 2002. 21p. (Documento n.199).

EVANS, J.R.; TERASHIMA, I. Effects of nitrogen nutrition on electron transport components and photosynthesis in spinach. Australian Journal of Plant Physiology, Melbourne, v.14 p.59-68, 1988.

FERNÁNDEZ, S. et al. Radiometric characteristics of Triticum aestivum cv. Astral under water and nitrogen stress. International Journal of Remote Sensing, London, v.15, n.9, p.1867-1884, 1994.

FREDEEN A.L. et al. Response of photosynthesis and carbohydrate partitioning to limitations in nitrogen and water availability in field-grown sunflower. Plant Cell and Environment, Oxford, v.14, p.963-970, 1991.

GARCEZ NETO, et al. Morphogenetic and structural responses of Panicum maximum cv. Mombaça on different levels of nitrogen fertilization and cutting regimes. Revista Brasileira de Zootecnia, Viçosa, v.31, n.5, p.1890-1900, 2002.

GILMORE, E.C. Jr.; ROGERS, J.S. Heat units as a method of measuring maturity in corn. Agronomy Journal, Madison, v.50, n.10, p.611-615, 1958.

GUITMAN, M.R. et al. Effect of source-sink relations and nitrogen nutrition on senescence and $\mathrm{N}$ remobilization in the flag leaf of wheat. Physiologia Plantarum, Oxford, v.82, p.278-284, 1991

HEALY, W. Viola x wittrockiana (Pansy). In: BALL, V. (Editor) Ball Red Book. 16.ed. Batavia: Ball Publ, 1998. p.777-782.

HODGES, T. Introduction. In: HODGES, T. Predicting crop phenology. Boston: CRC, 1991. p.1-2.

JENDIROBA, E.; CÂMARA, G.M.S. Rendimento agrícola da cultura da soja sob diferentes fontes de nitrogênio. Pesquisa Agropecuária Brasileira, Brasília, v.29, n.8, p.1201-1209, 1994.

JOEL, G. et al. Production efficiency in sunflower: the role of water and nitrogen stress. Remote Sensing of the Environment, Cleveland, v.62, p.176-188, 1997.

KIRBY, E.J. Factors affecting rate of leaf emergence in barley and wheat. Crop Science, Madison, v.35, n.1, p.11-19, 1995.

KLEPPER, B. et al. Quantitative characterization of vegetative development in small cereal grains. Agronomy Journal, Madison, v.7, p.780-792, 1982

MAKINO, A. et al. Distinctive responses of ribulose-1,5bisphosphate carboxylase and carbonic anhydrase in wheat leaves to nitrogen nutrition and their possible relationships to $\mathrm{CO}_{2}$ transfer resistance. Plant Physiology, Sendai, n.100, p.17371743,1992

MENGUEL, K.; KIRKBY, E.A. Principles of plant nutrition. 4.ed. Bern, Switzerland: Lang Druck, 1987. 685p.
Motos, J.R; Oliveira, M.J.G. (Coord). Produção de crisântemos em vaso. Holambra: Flortec, 1990. 34p.

RAIJ, B.V. Fertilidade do solo e adubação. Piracicaba: Ceres/ Potafos, 1991. 343p.

REID, M.S. Produce facts sunflower recommendations for maintaining postharvest quality. In: Postharvest Technology Research \& Information Center. Davis: University of California, 2004. Acesso em: 25 novembro 2005. On line. Disponível em: http://postharvest.ucdavis.edu/Produce/ ProduceFacts/orn/sunflower.pdf.

RICKMAN, R.W.; KLEPPER, B.L. The Phyllochron: where do we go in the future? Crop Science, Madison, v.35, n.1, p.44-49, 1995

SANGOI, L.; SILVA, P.R.F. Comparação entre métodos de cálculo de unidades térmicas e os dias do calendário na previsão de subperíodos de desenvolvimento do girassol. Pesquisa Agropecuária Brasileira, Brasília, v.21, p.901-908, 1986.

SCHOELLHORN, R. et al. Specialty cut flower production guides for Florida: sunflower. Gainesville: University of Florida, IFAS Extension, 2003. 3p.

SCHNEITER, A.A.; MILLER, J.F. Description of sunflower growth stages. Crop Science, Madison, n.21, p.901-903, 1981.

SKINNER, R.H.; NELSON, C.J. Elongation of the grass leaf and its relationship to the phyllochron. Crop Science, Madison, v.35, n.1, p.4-10, 1995

SMART, C.M. Gene expression during leaf senescence. New Phytologist, Lancaster, v.126, p.419-448, 1994.

SOARES, J.M. et al. Fertilizantes nitrogenados na produtividade de melão. Pesquisa Agropecuária Brasileira, Brasília, v.34, n.7, p. 1139-1143, 1999 .

STRECK, N.A. et al. Improving predictions of developmental stages in winter wheat: a modified wang and Engel model. Agricultural and Forest Meteorology, Amsterdam, v.115, n.2-3, p.139-150, 2003.

STRECK, N.A. et al. Estimativa do plastocrono em meloeiro (Cucumis melo L.). Ciência Rural, Santa Maria, v.35, n.6, p.1275-1280, 2005a.

STRECK, N.A. et al. Estimating leaf appearance rate and phyllochron in safflower (Carthamus Tinctorius L.). Ciência Rural, Santa Maria, v.35, n.6, p.1448-1450, 2005b.

TAIZ, L.; ZEIGER, E. Fisiologia vegetal. 3.ed. Porto Alegre: Artmed, 2004. 719p.

VILLALOBOS, F.J. et al. Oilcrop-sun: a development, growth and yield model of the sunflower crop. Agronomy Journal, Madison, v.88, p.403-415, 1996.

WILHELM, W.W.; McMASTER, G.S. Importance of the phyllochron in studying development and growth in grasses. Crop Science, Madison, v.35, n.1, p.1-3, 1995. 